\title{
Proinflammatory Caspase A Activation and an Antiviral State Are Induced by a Zebrafish Perforin after Possible Cellular and Functional Diversification from a Myeloid Ancestor
}

\author{
Mónica Varela Gabriel Forn-Cuní Sonia Dios Antonio Figueras Beatriz Novoa
}

Instituto de Investigaciones Marinas (IIM), CSIC, Vigo, Spain

\section{Key Words}

Perforins · Zebrafish · Evolution · MPEG1 - Virus ·

Inflammasome

\begin{abstract}
In mammals, perforins play a central role in the granule-dependent cell death induced by natural killer T cells and cytotoxic T lymphocytes, and participate both in the defense against virus-infected and neoplastic cells and in the recognition of nonself molecules by the immune system. Little is known about fish perforin genes. We examined the zebrafish with the aim of increasing our knowledge about the role of perforins. We characterized 6 perforin genes in the zebrafish genome, and we studied them at the evolutionary level in combination with expression patterns in several tissues and cell populations, during both larval development and in the course of a viral infection. Our results suggest the specialization of different cell types in the production of perforins. Moreover, functional diversification during the evolution of these molecules could be inferred from this study. In particular, one of the genes, prf19b, which is mainly produced by myeloid cells, seemed to be involved in antiviral defense, conferring protection after an in vivo infection.
\end{abstract}

(c) 2015 S. Karger AG, Basel

\section{KARGER}

E-Mail karger@karger.com

www.karger.com/jin

\section{Introduction}

Cytotoxic lymphocytes, made up of natural killer $\mathrm{T}$ cells and cytotoxic T lymphocytes, are cells that use their cytoplasmic granules to promote the cytolysis and apoptosis of target cells. Perforin plays a key role in secretory granule-dependent cell death, in defense against virusinfected and neoplastic cells [1] and also in the killing of other cells that are recognized as nonself by the immune system [2].

Perforin is expressed by cytotoxic $\mathrm{T}$ lymphocytes and natural killer $\mathrm{T}$ cells and forms pores in the membrane of target cells in the presence of calcium [3]. These pores cause not only the osmotic lysis of target cells but also the entry of molecules such as granzymes. Effective induction of apoptosis by cytotoxic lymphocytes requires both granzymes and perforin, although high concentrations of perforin alone can kill cells by necrosis [4]. Pore formation depends on the two characteristic domains of perforin: MACPF and CaLB [5]. The MACPF domain is also found in other molecules involved in the immune system, such as MPEG1 and complement components C6-C9. Furthermore, MPEG1, a protein produced exclusively by macrophages [6], has recently been identified as the precursor of perforin [7]. 
Knowledge about fish perforin genes is scarce, and these genes have only been characterized in 4 species [ 8 11]. Contrary to what occurs in higher vertebrates, fish species have more than 1 perforin gene in their genomes. As suggested by D'Angelo et al. [7], this fact could imply the existence of multiple or different functions for fish perforin genes.

In this study, we confirmed the existence of 6 perforin genes in zebrafish by sequencing and characterizing these genes. We studied their evolution, and also determined their differential constitutive expression and response to different stimuli in different organs and cell types. Moreover, we studied the changes in the expression of these genes throughout the first month of zebrafish development and their response to a systemic viral infection at 3 days post-fertilization (dpf). Our results could open doors to the study of possible new roles for fish perforins.

\section{Materials and Methods}

\section{Sequence Retrieval and Analysis}

Zebrafish perforin sequences were searched according to MACPF domain using the zebrafish genome assembly version Zv9 (www.ensembl.org/Danio_rerio/). Nine perforin genes were identified in the zebrafish genome using this method, but only 6 were selected for further analysis. The sequences were confirmed through PCR amplification using specific primers (online suppl. table S1; for all online suppl. material, see www.karger.com/ doi/10.1159/000431287) to obtain the full-length open reading frame (ORF) of each gene. The PCR products were subcloned into the $\mathrm{pCR}^{\circledR} 2.1$ vector (Invitrogen) and transformed into One Shot TOP10F competent cells (Invitrogen) for subsequent sequencing and ORF confirmation. The confirmed sequences were submitted to GenBank under accession numbers KP099718KP099723.

Identity and similarity analyses of the zebrafish perforin proteins were performed using MatGAT [12]. The domain distribution and signal peptide prediction were obtained using InterProScan 5 [13] and Phobius [14], respectively. The 3-dimensional structure of the zebrafish perforin proteins was predicted using the I-TASSER server [15], selecting the model with the best C-score, and was viewed using PyMOL (http://www.pymol.org). The template modeling score (TM-score), a measure of structural similarity between two proteins, was also analyzed to identify structural analogs with known crystal architecture in the Protein Data Bank (PDB; http://www.rcsb.org/pdb/).

Phylogenetic Tree and Analysis of Darwinian Selection

MPEG1, C6-C9 and PRF1 sequences were retrieved from the available published genomes in the Ensembl Genome Browser, v75 [16], and their phylogeny was studied as previously described by Forn-Cuní et al. [17].

To identify gene duplications and loss events during the evolution of the PRF1 family, a reconciliation $[18,19]$ of the obtained gene tree with their species phylogeny was performed, in which divergence times among fish species were retrieved from the TimeTree database when possible and from other published studies when data were missing $[20,21]$. The species tree was drawn with neighbor joining of the distance matrix using the R package APE v3.1-1 [22]. Finally, the most parsimonious reconciliation of the estimated gene tree and the species tree was performed with primetv [23] and was manually represented using Adobe Illustrator CS6.

\section{Animals}

Adult $\mathrm{RAG1}^{+/+}$and $\mathrm{RAG1}^{-/-}$zebrafish and their larvae were obtained from our experimental facility, where the fish were cultured using established protocols [24, 25]. Eggs were obtained according to protocols described in The Zebrafish Book [24] and maintained at $28.5^{\circ} \mathrm{C}$ in egg water $(5 \mathrm{mM} \mathrm{NaCl}, 0.17 \mathrm{mM} \mathrm{KCl}$, $0.33 \mathrm{mM} \mathrm{CaCl}_{2}, 0.33 \mathrm{mM} \mathrm{MgSO}_{4}$ and $0.00005 \%$ methylene blue). Fish care and the challenge experiments were conducted according to the guidelines of the CSIC National Committee on Bioethics under approval No. 07_09032012.

\section{Fish Challenge Experiments}

Adult zebrafish were intraperitoneally injected with $10 \mu \mathrm{l}$ of $1 \mathrm{mg} / \mathrm{ml}$ LPS, $10 \mu \mathrm{l}$ of $1 \mathrm{mg} / \mathrm{ml}$ poly I:C or $10 \mu \mathrm{l}$ of PBS. Kidneys were sampled from anesthetized fish at 3, 6 and 24 h post-stimulation (hps) and processed for gene expression analysis.

The Spring viraemia of carp virus (SVCV) isolate 56/70 was propagated on EPC cells (ATCC CRL-2872) and titrated in 96well plates. The $\mathrm{TCID}_{50} / \mathrm{ml}$ was calculated according to the protocol of Reed and Muench [26]. Adult zebrafish were intraperitoneally injected with $10 \mu \mathrm{l}$ of $3 \times 10^{6} \mathrm{TCID}_{50} / \mathrm{ml}$. Zebrafish larvae were infected with SVCV through microinjection into the duct of Cuvier, as described by Benard et al. [27], at $3 \mathrm{dpf}$. A total of $2 \mathrm{nl}$ of a 1:20 dilution of the $3 \times 10^{6} \mathrm{TCID}_{50} / \mathrm{ml} \mathrm{SVCV} \mathrm{stock} \mathrm{was} \mathrm{mi-}$ croinjected per larva. PBS microinjection was used as a control in the experiments with larvae. To monitor the progression of the infection in larvae, we checked by qPCR the SVCV N gene transcription and the $m x$ gene (a and b paralogs) transcription (online suppl. fig. S1).

\section{Kidney Cell Population Sorting}

Kidney leukocytes from adult fish were prepared for analysis and sortingbased on forward-and side-scatter, using a FACSCalibur flow cytometer (Becton Dickinson) equipped for cell sorting, as described by Traver et al. [28]. A total of 100,000 events were sorted from the regions corresponding to the myeloid (R2), lymphoid (R3) and precursor (R4) populations, pelleted by centrifugation at $4,000 \mathrm{~g}$ for $5 \mathrm{~min}$ at $4^{\circ} \mathrm{C}$ and processed for gene expression analysis. The cells from the total population (non-sorted) were also processed for RNA isolation. To confirm the identity of the 3 leukocyte fractions sorted by flow cytometry, specific cell markers (marco for macrophages, $m p x$ for neutrophils, $c d 4$ and $c d 8 a$ for T lymphocytes) were amplified by qPCR (online suppl. fig. S2).

\section{RNA Isolation and Gene Expression}

Total RNA was isolated using the Maxwell ${ }^{\circledR} 16 \mathrm{LEV}$ simplyRNA tissue kit (Promega) and the automated Maxwell ${ }^{\circledR} 16$ Instrument according to the manufacturer's instructions. cDNA synthesis using random primers and $\mathrm{qPCR}$ were performed as previously described [29]. The Pfaffl method was used to evaluate the efficiency of the primer pairs using serial 5-fold dilutions of cDNA and cal- 
culating the slope of the regression line of the cycle thresholds (Cts) versus the relative concentration of cDNA. The $18 \mathrm{~S}$ gene was used as a housekeeping gene to normalize the expression values (primers specified in online suppl. table S1). Fold-change units were calculated by dividing the normalized expression values of infected larvae by the normalized expression values of the controls.

\section{Plasmid Construction}

A selected zebrafish perforin (prf19b) was amplified by PCR (primers in online suppl. table S1), and the PCR product was cloned using the pcDNA 3.1/V5-His TOPO TA expression kit (Invitrogen). One Shot TOP10F competent cells (Invitrogen) were transformed to generate the plasmid constructs. Plasmid purifications were conducted using the PureLink HiPure plasmid midiprep kit (Invitrogen). The recombinant plasmids were microinjected into one-cell-stage zebrafish embryos with a glass microneedle using a Narishige MN-151 micromanipulator and a Narishige IM-30 microinjector. Each egg was microinjected with $100 \mathrm{pg}$ of the corresponding plasmid in a final volume of $2 \mathrm{nl}$. An additional untreated group was included to control for egg quality and survival. Three days after plasmid administration, the larvae were microinjected with $2 \mathrm{nl}$ of an SVCV suspension at a final concentration of $1.5 \times 10^{5} \mathrm{TCID}_{50} / \mathrm{ml}$ into the duct of Cuvier. The fish culture conditions were controlled 3 times per day. Three days after plasmid administration, samples were taken to measure caspase-1 activity and to perform RNA isolation.

\section{Caspase-1 Activity Measurement}

Total protein was obtained from 25 larvae/biological replicates after their homogenization in lysis buffer (25 mM HEPES, $5 \mathrm{mM}$ EGTA, $5 \mathrm{mM}$ DTT and protease inhibitor). Caspase- 1 activity in $75 \mu \mathrm{g}$ of total protein/technical replicate was determined using AcYVAD-AFC (Calbiochem, 688225) as a substrate. A total of $1 \mu \mathrm{l}$ of the substrate was added per well, and after an incubation of $90 \mathrm{~min}$ at $25^{\circ} \mathrm{C}$, the fluorescence was measured (exc. 405, emi. 492). The experiment was repeated twice, with 2 biological replicates and 3 technical replicates per group and experiment.

\section{Statistical Analysis}

The results are expressed as the mean \pm standard error. Significant differences were determined using one-way analysis of variance (ANOVA) followed by Tukey's multiple comparison test. The differences were considered statistically significant when $\mathrm{p} \leq$ 0.05 .

\section{Results}

Defining the Complete Repertoire of Perforin Genes in Zebrafish

Using the zebrafish Ensembl Genome version Zv9, we identified 9 annotated perforin genes: prf1.9p (ENS DARG00000093777), prf1.5 (ENSDARG00000037598), prf1.3 (ENSDARG00000001572), prf1.6 (ENSDARG 00000024522), prf1.2 (ENSDARG00000021444), prf1.8 (ENSDARG00000089259), prf1.7 (ENSDARG00000073

Cellular and Functional Diversification of

Zebrafish Perforins
969), prf1 (ENSDARG00000060662) and prf1.1 (ENS DARG00000030394). Of these, prf1 and prf1.1 were located on chromosome 3, prf1.5 and prf1.6 on chromosome 8 and the other 5 on chromosome 19 (fig. 1a). Of the perforin genes situated on chromosome 19, prf1.9p was identified in the database as a pseudogene, so we decided to remove it from the characterization. Furthermore, amplifications obtained for the prf1.8 gene did not produce a complete protein, and so it was also discarded from the characterization. In addition, prf 1.7 was $100 \%$ identical (CDS and UTRs) to prf1.2 and indistinguishable by PCR. Although this finding could have been due to gene duplication, we could not rule out a certain type of error during the assembly of this region of the genome. We only considered prf1.2. In summary, after confirming all of the perforin sequences, we performed our study on 6 perforin genes, which were renamed according to their chromosomal positions: $p r f 3 a$ and prf $3 b$ on chromosome 3, prf8a and prf8b on chromosome 8 and prf19a and prf19b on chromosome 19 (fig. 1a).

\section{Sequence Analysis and Structural Domains}

The study of the domain structure of the 6 perforin genes revealed the presence of the two characteristic domains: MACPF and CaLB (fig. 1b). The zebrafish perforin genes had an amino acid number between 516 and 588 , with the perforins on chromosome 8 being the shortest and those on chromosome 3 being the longest. The variation in length sequences was mainly observable after the CaLB domain. Regarding the identity and similarity between the zebrafish perforins (fig. 1b), the high values observed between Prf8a and Prf8b should be noted (85.9 and $74.7 \%$, respectively). The perforin genes on chromosome 3 were also relatively similar, with $69.4 \%$ identity and $51.5 \%$ similarity. Prf $19 \mathrm{~b}$ showed identity values ranging between 59.2 and $54.1 \%$ with all perforin genes (similarity ranging between 38.7 and $33.2 \%$ ), with Prf3a being the nearest perforin. We also examined the tridimensional predicted structure of the perforin proteins (fig. 1c). The TM-scores observed for the zebrafish perforins revealed that the X-ray crystal structure of the Mus musculus lymphocyte perforin was the best template for all of the proteins (TM-scores ranging between 0.92 and 0.98 ).

\section{Analysis of Darwinian Selection and Phylogenetic \\ Tree}

We estimated the $\mathrm{dN} / \mathrm{dS}$ ratios $(\omega)$ among the zebrafish perforin sequences to quantify the evolutionary pressure acting on the perforin genes and determined that there was no positive selection pressure $(\omega=0.35$; fig. $2 a)$. 


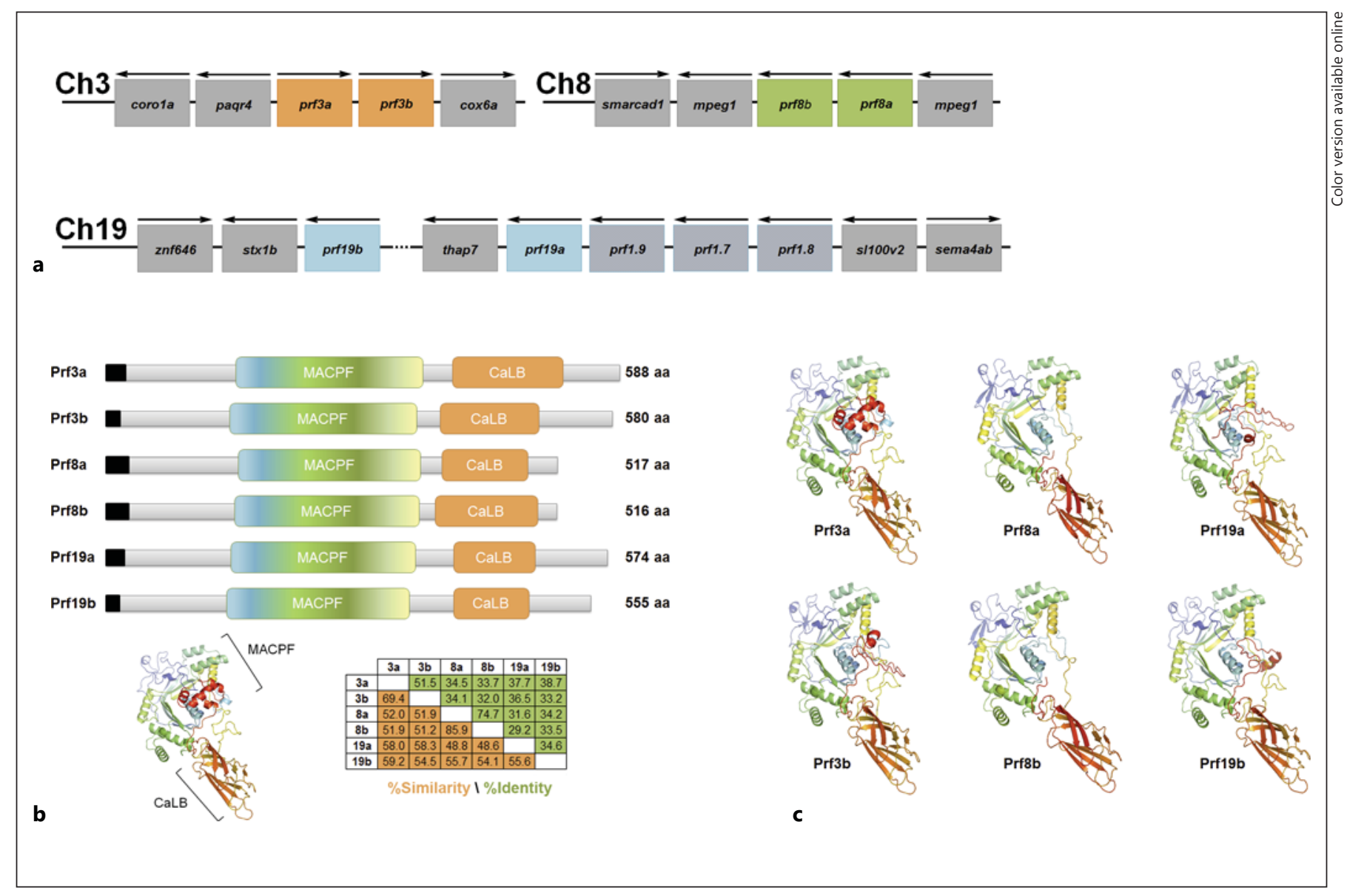

Fig. 1. Sequence location and structural domains of zebrafish perforin genes. a Gene location of perforin sequences on zebrafish chromosomes (Ch)3, 8 and 19. b Domain structure of 6 perforin genes showing the signal peptide (black) and the MACPF and CaLB characteristic domains. The figure shows the position of these domains in a 3-dimensional reconstruction of a perforin molecule. The percentages of similarity (orange) and identity (green) between the zebrafish perforin genes are displayed on the chart. c 3-Dimensional structure of zebrafish perforins predicted using the I-TASSER server, with selection of the model with the best C-score, and viewed using PyMOL.
The unreconciled gene tree (see online suppl. fig. S3) was not completely resolved, as 1 clade was found to be ambiguous: the Latimeria chalumnae prf1.1 gene was found both on the vertebrate $P R F 1$ and grouped with the rest of the perforin genes in its genome. In the subsequent analysis, we represented the topology concurrent with the vertebrate PRF1 evolution. Phylogenetic reconciliation of the perforin gene tree with the evolution of the fish species confirmed that this is a very dynamic gene family, with as many as 20 predicted gene duplications in only the fish lineage (fig. 2b). An invertebrate MPEG1-like gene (represented by Crassostrea gigas MPEG1 in this study) seems to be the most likely ancestral gene from which both the final components of the complement cascade and perforins evolved. Presumably, the C6-C9/PRF precursor originated in the chordate lineage, based on the presence of many C6-like genes in the Ciona intestinalis genome. No MACPF domain-containing genes were found in the European or Japanese lamprey's current genome. The earliest branching species with a prf1 sequence was Callorhinchus milii, which suggests that perforins appeared during or after the $1 \mathrm{R}$ and $2 \mathrm{R}$ whole-genome duplications. It is important to note that based on similarity, zebrafish prf19b seems to be the one-to-one ortholog to both mammalian and shark PRF1. The analysis suggests that the ancestor of the zebrafish genes $\operatorname{prf} 19 a / 3 a / 3 b$ and $\operatorname{prf} 8 a / 8 b$ arose in this time frame from a duplication of the prf19b gene (fig. 2c). Later, the fish genome duplication (3R) differentiated prf19a and prf3b, but it was not until the Danio rerio and Astyanax mexicanus common ances- 


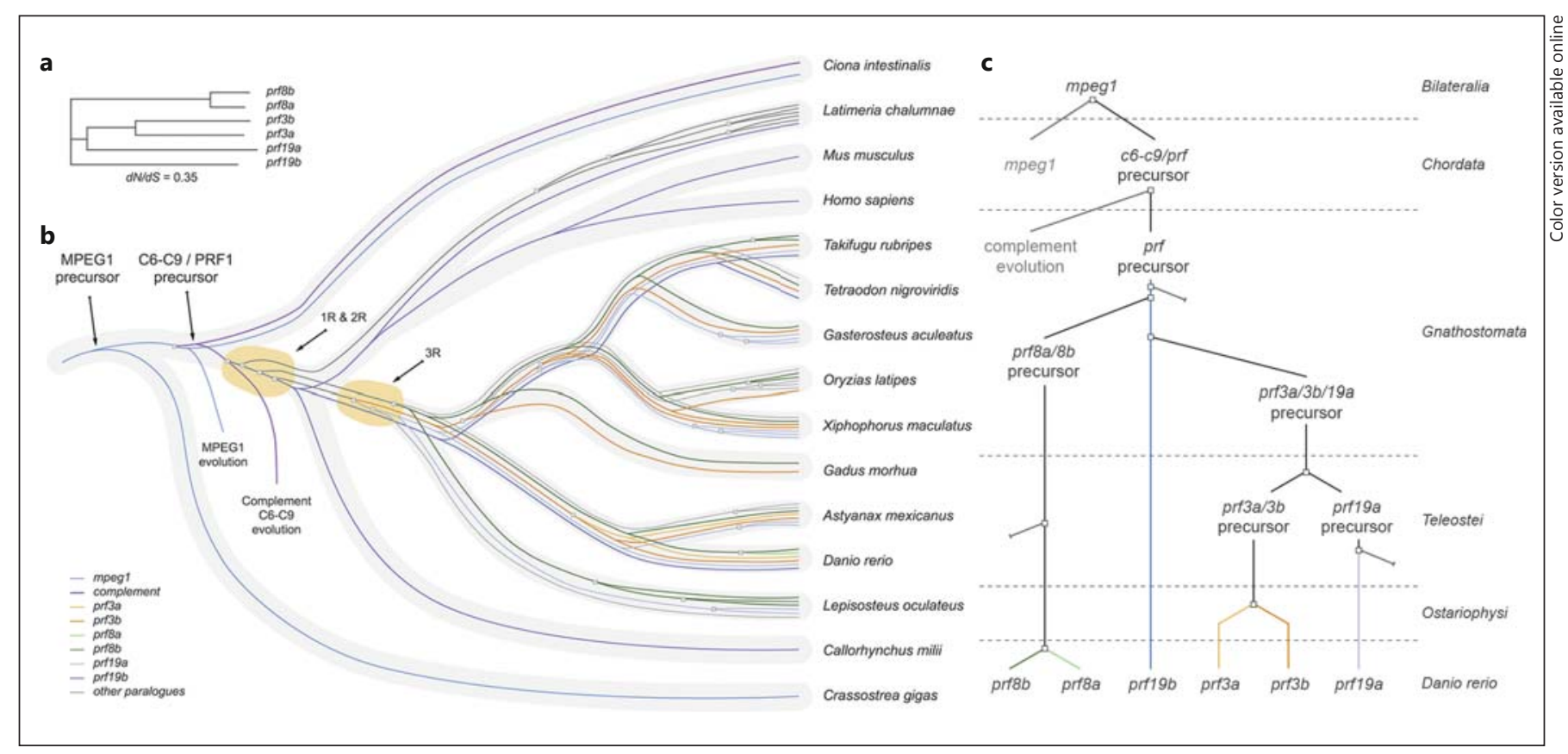

Fig. 2. Darwinian selection and phylogenetic tree. a The $\mathrm{dN} / \mathrm{dS}$ ratio among the zebrafish perforin sequences was calculated to quantify the evolutionary pressure acting on these genes. b Reconciliation of the PRF family within vertebrate evolution, focusing on the fish with sequenced genomes. The reconciliation suggests that the most probable time frame for the origination of the perforin gene was during or after the $1 \mathrm{R}$ and $2 \mathrm{R}$ genome duplication time frames. 3R indicates the fish-specific genome duplication. c Schematic representation of the gene evolution of the studied zebrafish prf genes. The time frames represent the most recent taxonomic classification, in which the duplications (shown as squares) are predicted and the truncated lines represent other PRF paralogs not found in the zebrafish genome.

ing 13 and 20\%, respectively, of the total perforin gene expression. The expression of prf $19 b$ and $p r f 3 a$ was minimal in the kidney and gill.

\section{Ontogeny of Perforin Genes in Zebrafish Larvae}

We also analyzed the constitutive expression of the Genes

The presence of 6 perforin genes led us to investigate whether there was differential constitutive expression in 6 adult zebrafish tissues. The perforin genes on chromosome 8 (prf8a and prf8b) showed high basal expression in all analyzed tissues (fig. 3a). In contrast, the perforin genes on chromosomes 3 and 19 had differential expression between the compared tissues, with prf $3 a$ and prf $19 b$ being the perforins with lower expression. When we compared the levels of perforins between the analyzed tissues, the gill and spleen were the tissues with higher perforin gene expression (fig. 3b). Regarding the relative proportions of expression of the perforin genes in the analyzed tissues, prf 8 a predominated in all analyzed tissues, with the exception of the muscle, in which prf $8 b$ expression was more present (fig. 3c). The presence of prf19a expression in the kidney and spleen was remarkable, represent-

Cellular and Functional Diversification of Zebrafish Perforins perforin genes during the ontogeny of larvae from 1-29 dpf. We observed different expression patterns along the development of zebrafish larvae for different perforin genes (fig. 4a). The gene prf3a showed two peaks of expression throughout larval development, with the first at $1 \mathrm{dpf}$ and the second at $23 \mathrm{dpf}$. The gene prf $3 b$ showed the highest expression at $23 \mathrm{dpf}$, and this was also observed for prf19b. It must be noted that prf19b also exhibited a great increase in expression between days 5 and 8 . Moreover, in the case of prf19a, a peak of expression was evident at $5 \mathrm{dpf}$. Regarding the perforin genes located on chromosome $8, \operatorname{prf} 8 a$ expression peaked at $2 \mathrm{dpf}$, and a considerable increase in expression was detected at $29 \mathrm{dpf}$ in the case of prf $8 b$. Considering the expression of all of the perforin genes over time, we found that the prevailing perforin by far was prf8a (fig. 4b). 


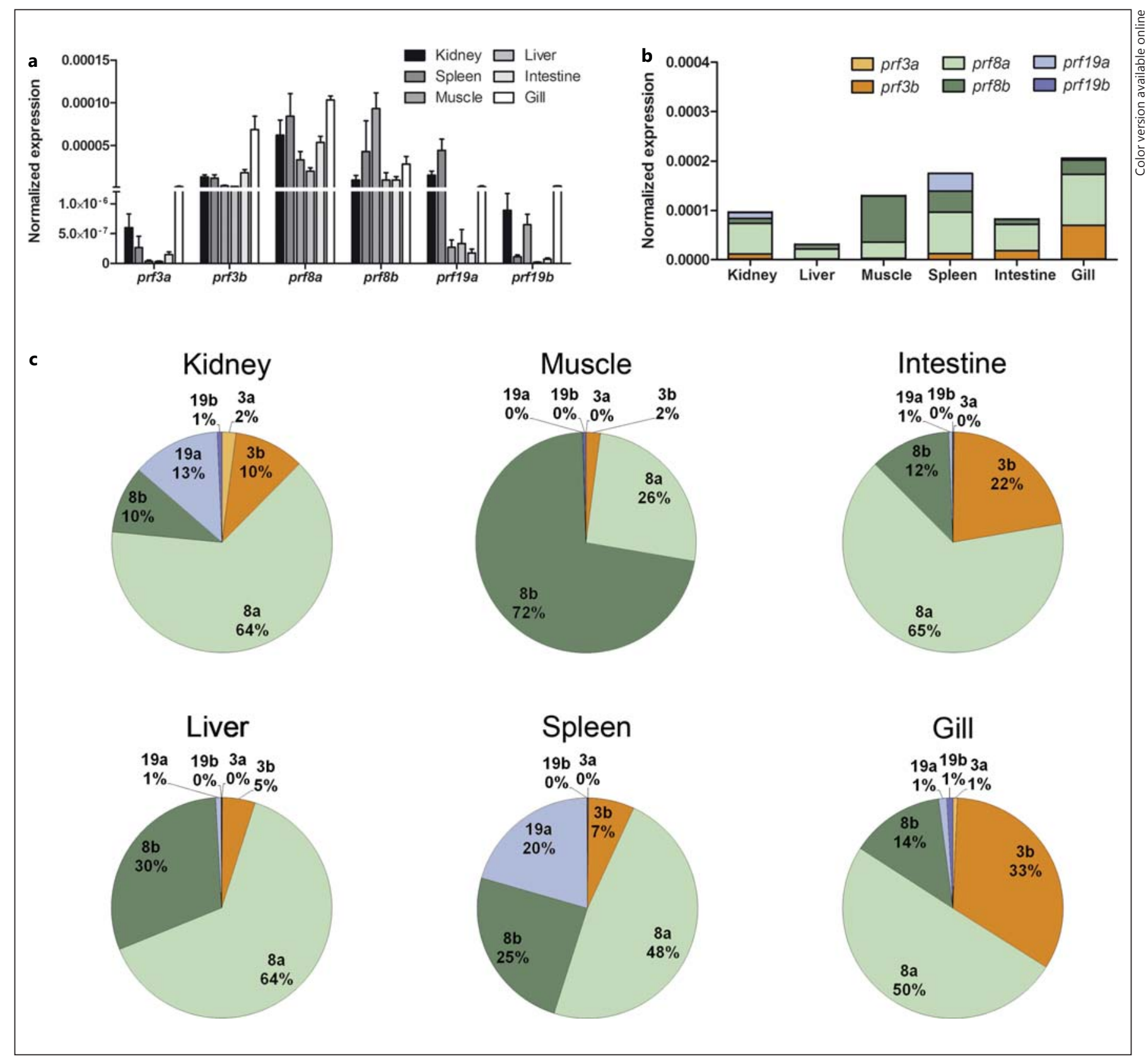

Fig. 3. Constitutive tissue-specific expression. a Normalized expression of zebrafish perforin genes in the kidney, spleen, muscle, liver, intestine and gill. The graphs represent the mean \pm standard error of 4 independent biological replicates. $\mathbf{b}$ Cumulative normalized expression of zebrafish perforin genes in different tissues. The relative expression of each perforin gene was normalized to the expression level of the $18 \mathrm{~S}$ ribosomal RNA gene in the same tissue. c Relative proportion (\%) of the perforin transcripts in different zebrafish tissues.

\section{Perforin Genes in Adult Kidney Cell Populations}

Given the heterogeneous response observed among the 6 zebrafish perforin genes, we wanted to check the expression of these genes in different cell populations in the adult kidney. We separated the 3 principal cell pop- ulations in the kidney, i.e. the lymphoid, myeloid and precursor populations, by FACS (fig. 5a). The lymphoid population showed the highest perforin expression, highlighting, in particular, the presence of prf8a and prf $3 b$ (fig. 5b). Expression of the prf $3 b$ gene accounted 


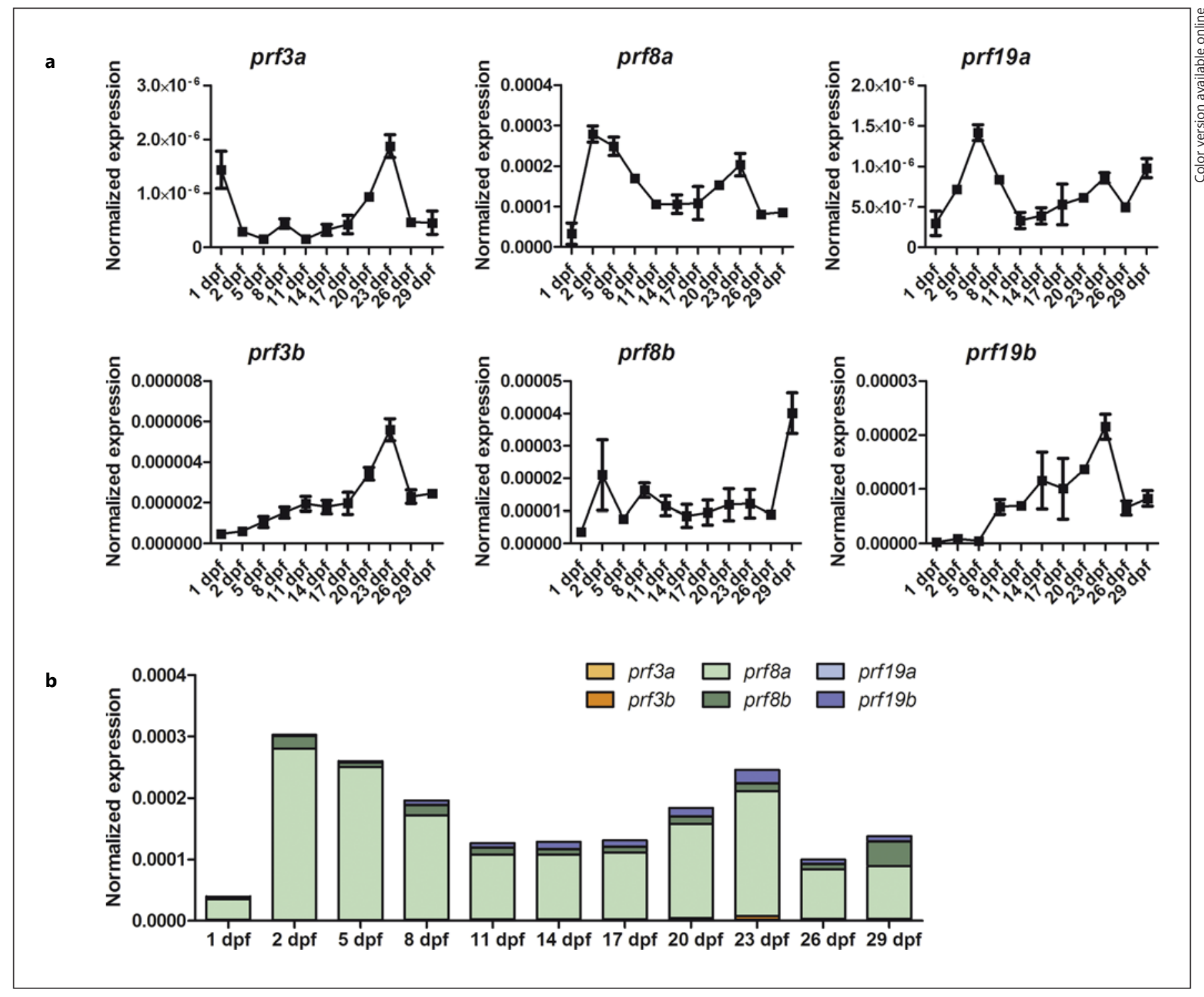

Fig. 4. Perforin gene expression during zebrafish larvae ontogeny. a Normalized expression of zebrafish perforin genes during the development of zebrafish larvae between 1 and $29 \mathrm{dpf}$. The graphs represent the mean \pm standard error of 3 independent biological replicates. b Cumulative normalized expression of perforin genes during the first month of larval life. The relative expression of each perforin gene was normalized to the expression level of the $18 \mathrm{~S}$ ribosomal RNA gene in the same sample. for 1 and $2 \%$ of total perforin expression in the myeloid and precursor populations, respectively, which was in contrast to the $23 \%$ observed in the lymphoid population (fig. 5c). We also noted that prf19b was most represented in the myeloid and precursor populations, accounting for 18 and $15 \%$, respectively, of total perforin expression. The prf $19 b$ was poorly represented in the lymphoid population, accounting for $1 \%$ of total perforin expression. This finding led us to suspect that there might be functional differences between the 6 perforins.

\section{RAG1 ${ }^{-/-}$Fish Showed a Different Perforin Expression Pattern}

Because the lymphoid population showed the highest perforin expression, we used mutant $\mathrm{RAG1}^{-/-}$fish, a line that has no mature $\mathrm{T}$ or $\mathrm{B}$ lymphocytes [30], to determine the existence of differential cellular expression among the 6 perforin genes within these mutants relative to $\mathrm{RAG}^{+/+}$fish. Analyzing the amount of perforins in the kidney of $\mathrm{RAG1}^{-/}$fish, we observed that the mutant expressed more perforin transcripts than the con- 


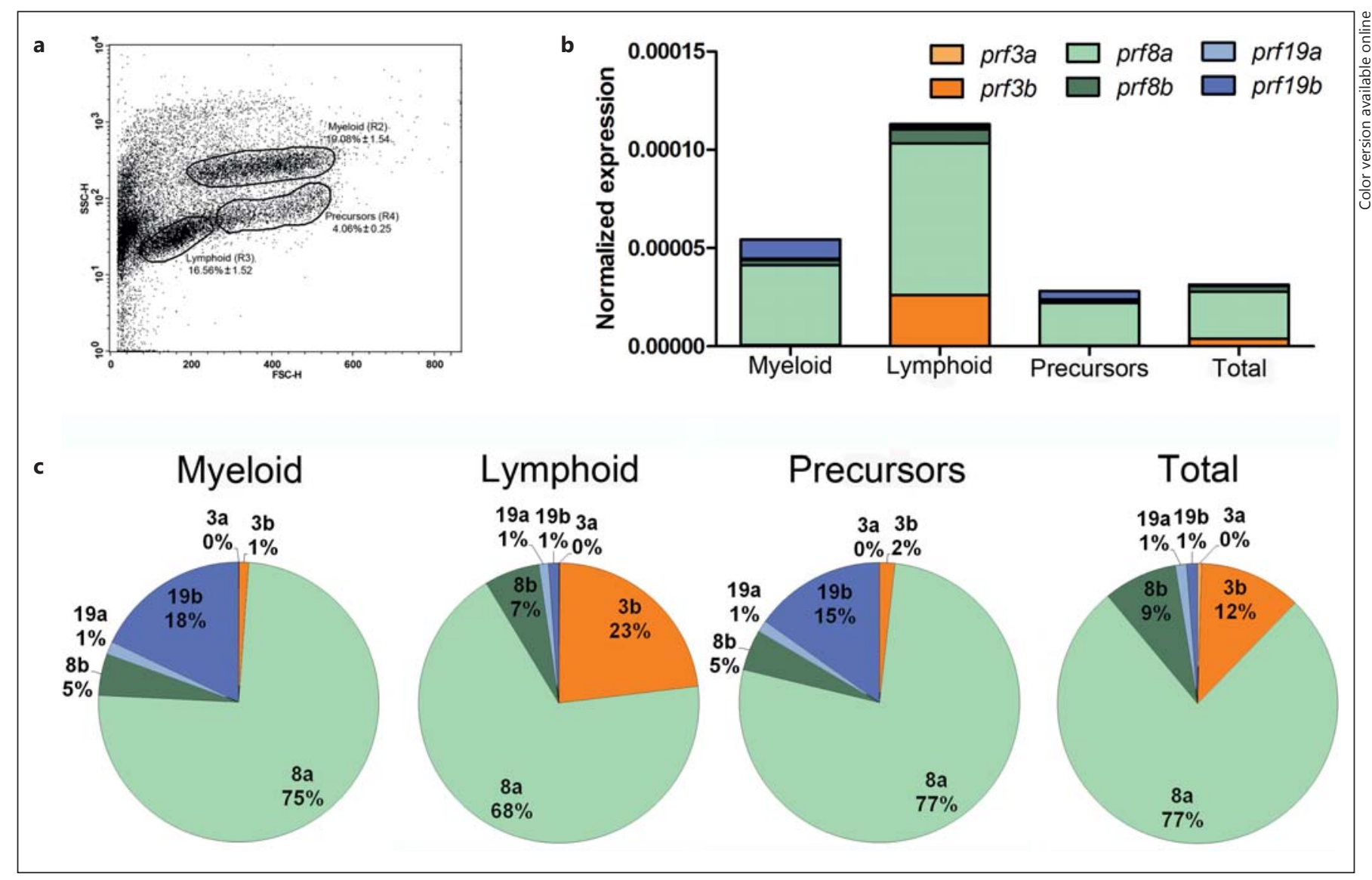

Fig. 5. Perforin expression in adult kidney cell populations. a Flow cytometry analysis of cell populations from the zebrafish kidney based on cell size (forward-scatter; FSC-H: voltage E00/mode Lin) and granularity (side-scatter; SSC-H: voltage 350/mode log). R2, R3 and R4 represent the myeloid, lymphoid and precursor populations, respectively. $\mathbf{b}$ Cumulative normalized expression of zebraf- ish perforin genes in the sorted cell populations from the kidney and in total (non-sorted) cells. The expression of each perforin was normalized to the expression of the $18 \mathrm{~S}$ ribosomal RNA gene. c Relative proportion (\%) of the perforin transcripts in each population and in total cells. trol fish did, with prf3a and prf19a expression predominating (fig. 6a). The gene prf3a showed an 11-fold change in expression in $\mathrm{RAG1}^{-/-}$compared with $\mathrm{RAG}^{+/+}$fish, and prf19a expression increased nearly 60 -fold (fig. 6b). Another gene that showed significantly higher expression in the mutant fish was prf19b. Only prf8a showed significantly lower expression in $\mathrm{RAG1}^{-/-}$fish.

\section{Modulation of Perforin Genes upon Challenge in the \\ Adult Kidney}

Once we determined that the zebrafish perforins showed different tissue/cell expression profiles, we evaluated the in vivo effect of LPS, poly I:C and SVCV in the adult kidney at 3, 6 and $24 \mathrm{~h}$ post-injection (hpi). Again, prf $8 a$ and prf8b showed a similar response with all the stimuli used (fig. 7). The gene prf $3 b$ was upregulated at 6 and $24 \mathrm{hpi}$ with SVCV and LPS after $6 \mathrm{~h}$, and prf3a was also upregulated after SVCV and LPS injection, but at 3 and 6 hpi. Regarding prf19a, the inhibition induced after poly I:C administration and the upregulation at $24 \mathrm{hpi} \mathrm{in-}$ duced by LPS were remarkable. The gene prf19b showed a curious pattern of expression, with a strong inhibition at $3 \mathrm{~h}$ with any of the stimuli administered to the fish. Considering that the injection was intraperitoneal, this could be related to the migration of certain cell type in the kidney to the peritoneal cavity. Interestingly, the expression of prf $19 \mathrm{~b}$ increased to a 3-fold change with SVCV at $6 \mathrm{~h}$.

\section{Perforin Response in SVCV-Infected Larvae}

We next investigated the role of perforin genes in the response against SVCV in zebrafish larvae with a time course infection experiment (from 3 to $24 \mathrm{hpi}$ ) compar- 
ing infected and non-infected fish. The expression profiles over time showed the behavior of different perforin genes during SVCV infection (fig. 8a). In general, the response of perforin genes to SVCV was not high, with the exception of prf $3 b$ and prf $19 b$ that showed a more robust response from $12 \mathrm{hpi}$. The gene prf19a was the only gene that did not seem to respond to the virus. By plotting the percentage of each perforin over time during infection compared to uninfected fish, we observed the largest differences at $24 \mathrm{hpi}$ (fig. 8b). At this point, prf3b and prf $19 b$ expression was higher ( 8 and $15 \%$ of the total, respectively) compared with expression in uninfected fish.

\section{Prf19b Conferred Protection against Systemic SVCV}

Infection in Zebrafish Larvae

As prf $19 b$ was the most expressed perforin in the myeloid population, and considering its response to SVCV in zebrafish larvae, we wanted to analyze its importance in the resolution of the infection. In the antiviral response to this virus, macrophages are particularly important; it has been described that these cells may be the primary target of the virus, dying due to pyroptosis after caspase a activation and IL1 $\beta$ release [31]. With the aim of inducing overexpression of Prf19b in zebrafish larvae, we microinjected an expression plasmid into one-cell-stage zebrafish eggs. The expression of prf $19 b$ in these larvae was 3,000 times higher than in control larvae at $3 \mathrm{dpf}$ (fig. 9a). No mortalities or defects in the development of prf $19 b$-overexpressing larvae were observed. After a challenge with SVCV at $3 \mathrm{dpf}$, these prf19b-overexpressing larvae showed enhanced survival compared with control larvae at $72 \mathrm{hpi}$ ( 80 vs. $45 \%$, respectively; fig. 9 b). Since inflammation and pyroptosis after caspase a activation have been shown to play an important role during SVCV infection in zebrafish larvae [31], we checked whether prf19b overexpression could affect these processes by a qPCR analysis of $i l 1 \beta$. This proinflammatory cytokine appeared to be up-

Fig. 6. Perforin gene expression pattern in the kidney of $\mathrm{RAG1}^{-/-}$ fish. a Cumulative normalized expression of zebrafish perforin genes in $\mathrm{RAG1}^{+/+}$and $\mathrm{RAG1}^{-/-}$fish. The relative expression of each perforin gene was normalized to the expression level of the $18 \mathrm{~S}$ ribosomal RNA gene in the same sample. $\mathbf{b}$ Expression of each perforin gene in $\mathrm{RAG}^{+/+}$and $\mathrm{RAG}^{-/-}$fish. The fold change was calculated by dividing the normalized expression values in $\mathrm{RAG}^{-/-} \mathrm{ze}-$ brafish by the normalized expression values obtained in $\mathrm{RAG}^{+/+}$ zebrafish. The graphs represent the mean \pm standard error of 4 independent biological replicates. The asterisks denote statisticallysignificant differences with respect to the $R A G 1^{+/+}$group. Significant differences are displayed as $* * *(0.0001<\mathrm{p}<0.001)$, ** $(0.001<$ $\mathrm{p}<0.01)$ or $*(0.01<\mathrm{p}<0.05)$.

Cellular and Functional Diversification of Zebrafish Perforins

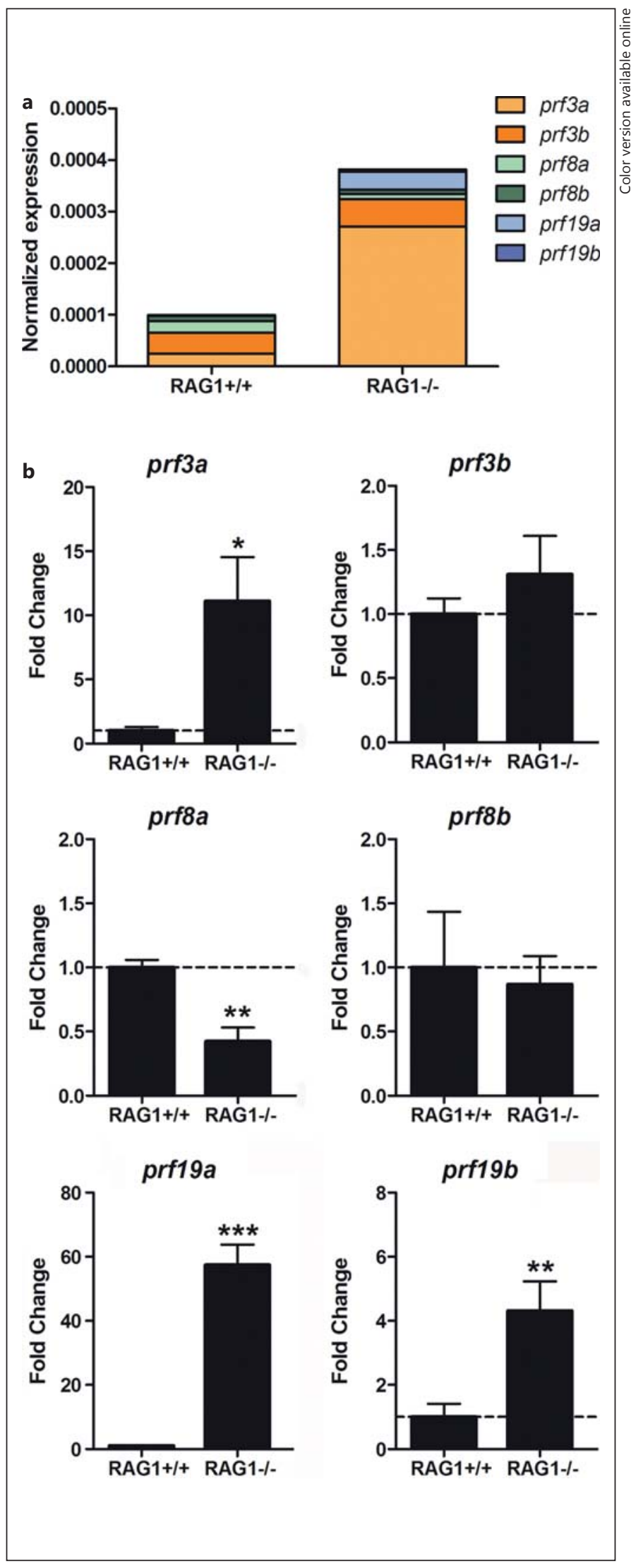

J Innate Immun 2016;8:43-56 DOI: $10.1159 / 000431287$ 
regulated 12-fold as a consequence of prf19b overexpression at $3 \mathrm{dpf}$ (fig. 9c). Recent publications have described the cleavage of zebrafish IL1 $\beta$ by the caspase- 1 homolog caspase a [32]. We observed that prf19b overexpression triggers the activation of caspase a at $3 \mathrm{dpf}$ at the transcriptional and translational levels, as observed based on increases in caspase a expression and caspase-1 activity, respectively (fig. 9d).

\section{Discussion}

In contrast to mammals, fish species possess more than 1 perforin gene in their genomes. We were able to confirm the existence of 6 perforin genes in zebrafish, located on chromosomes 3, 8 and 19. These genes possess the characteristic MACPF and CaLB domains, which are needed for pore formation in the plasma membrane of target cells [33].

The phylogenetic analysis of the perforin gene family evolution in fish confirmed previous published results [7]: the perforin ancestor gene differentiated from MPEG1 via a common precursor of $\mathrm{C} 6-\mathrm{C} 9$ and $\mathrm{PRF}$ in the chordate lineage. Furthermore, the presence of C6-like genes and the absence of PRF in the Ciona intestinalis and Ciona savignyi genomes suggest that the complement gene family probably evolved first. As an update to the referenced study, we found a partial PRF1 sequence in the elephant shark genome, confirming the presence of $P R F 1$ in the Chondrichthyes lineage and its origin prior to the evolution of jawed vertebrates. However, the notable absence of any MACPF domain-containing gene in the se-

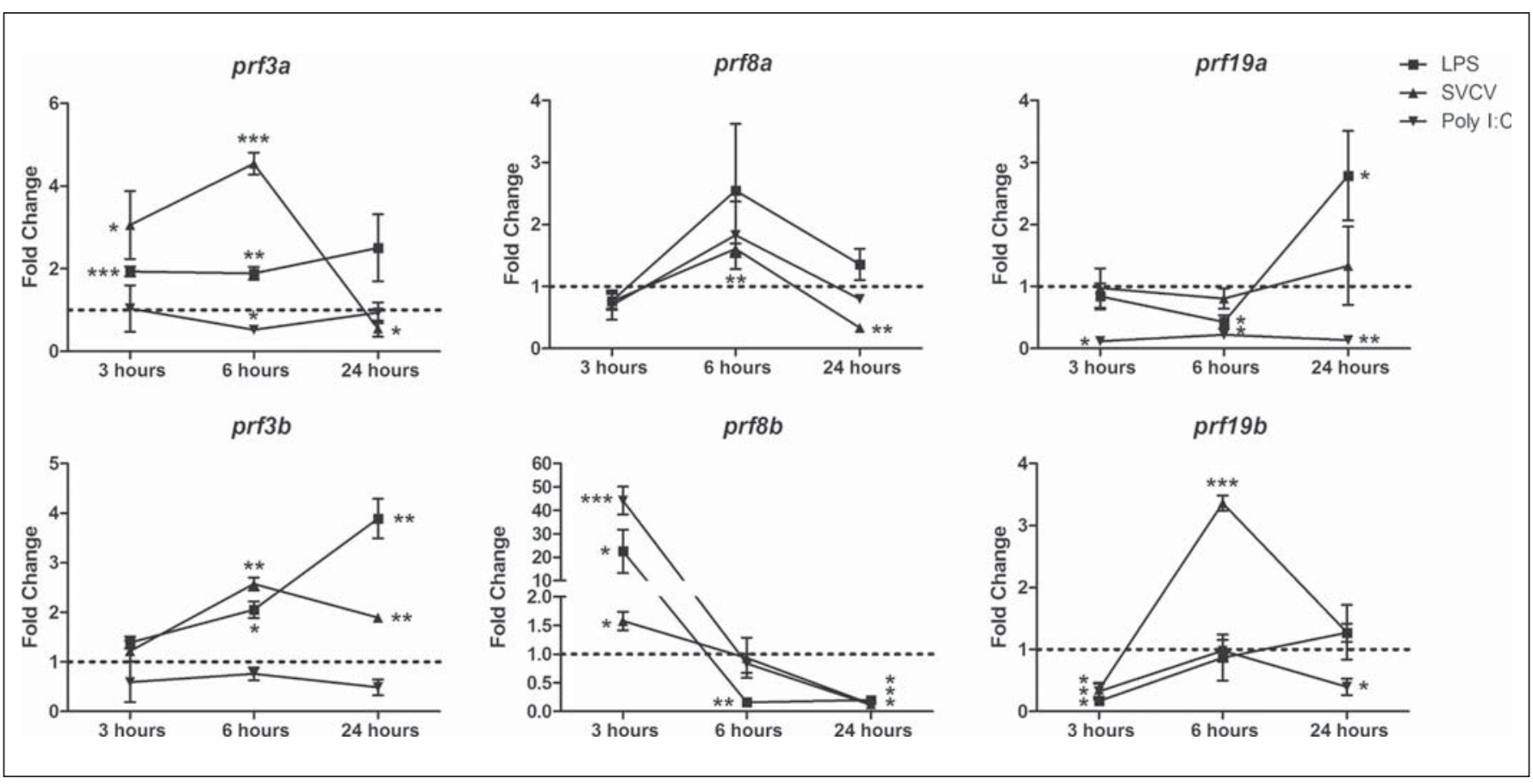

Fig. 7. In vivo effect of LPS, poly I:C and SVCV in the adult kidney. Expression of perforin genes in the zebrafish adult kidney 3, 6 and $24 \mathrm{~h}$ after challenge. The expression level of each gene was expressed as the fold change with respect to the levels detected in the control group (injected with $\mathrm{PBS}$ ). The graphs represent the mean \pm standard error of 4 independent biological replicates. The asterisks denote statistically significant differences with respect to the control group. Significant differences are displayed as $* * *(0.0001<\mathrm{p}<0.001)$, ** $(0.001<\mathrm{p}<0.01)$ or $*(0.01<\mathrm{p}<0.05)$.
Fig. 8. Perforin response in SVCV-infected larvae. a Expression of perforin genes between 3 and 24 hpi with SVCV. The fold change was calculated by dividing the normalized expression values in infected larvae by the normalized expression values obtained in control individuals (injected with PBS). The graphs represent the mean \pm standard error of 3 independent biological replicates. The asterisks denote statistically significant differences with respect to the control group. Significant differences are displayed as *** $(0.0001<\mathrm{p}<0.001)$, ** $(0.001<\mathrm{p}<0.01)$ or $*(0.01<\mathrm{p}<0.05)$. b Relative proportion (\%) of perforin transcripts in zebrafish larvae during the SVCV challenge.

(For figure see next page.) 


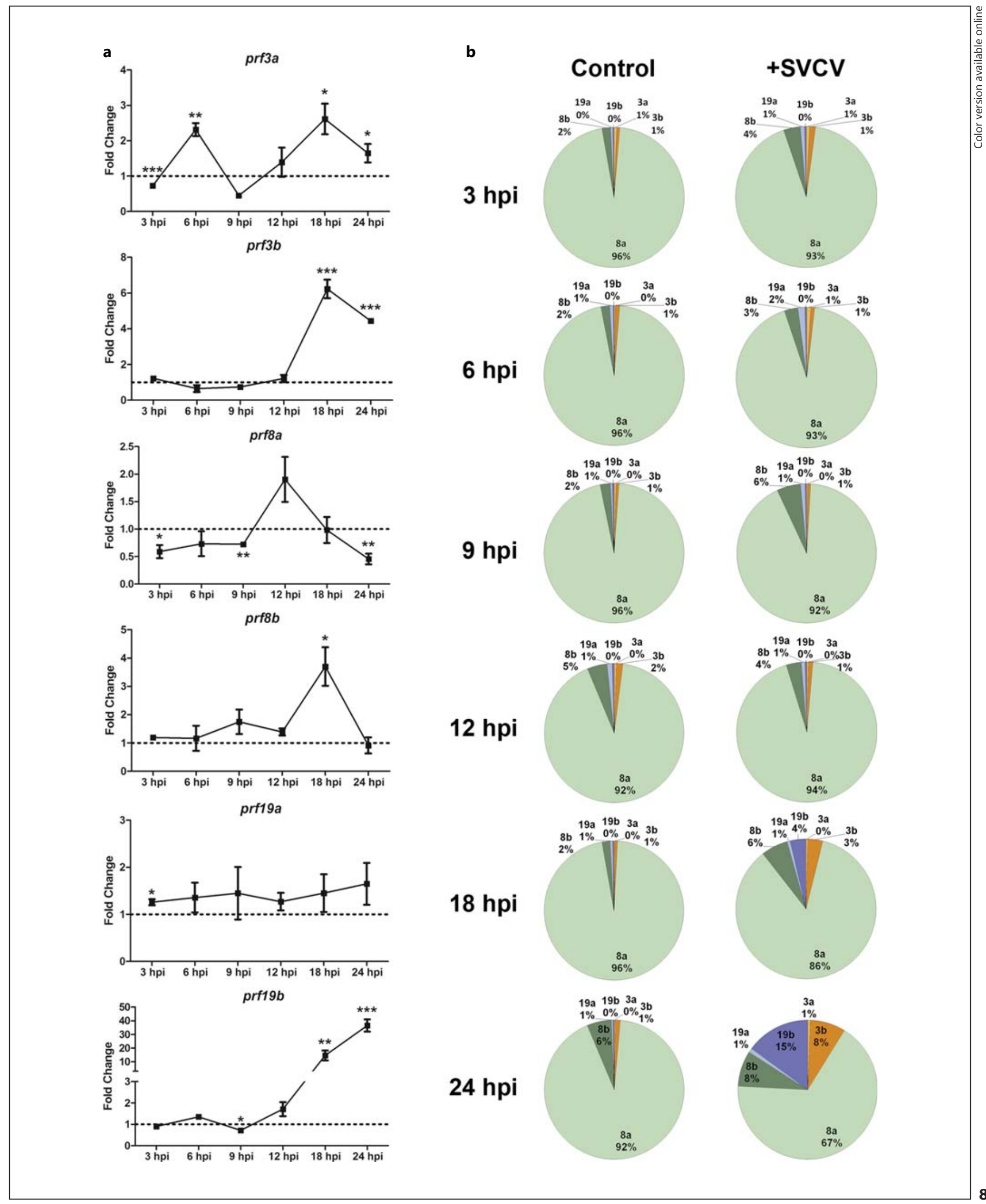

Cellular and Functional Diversification of Zebrafish Perforins 
Fig. 9. Overexpression of prf19b and inflammatory response in zebrafish larvae. a Expression of prf $19 b$ in zebrafish larvae injected with Prf19b expression plasmid at 3 dpf. b Kaplan-Meier survival curve after infection with SVCV $(\mathrm{p}<0.001)$. c Expression of $i l 1 \beta$ in zebrafish larvae injected with Prf19b expression plasmid at 3 dpf. d Expression of caspase $a$ and caspase a activity (arbitrary units) in zebrafish larvae injected with Prf19b expression plasmid at $3 \mathrm{dpf}$. The fold change was calculated by dividing the normalized expression values in larvae injected with Prf19b plasmid by the normalized expression values obtained in larvae injected with empty plasmid. The graphs represent the mean \pm standard error of 3 independent biological replicates. The asterisks denote statistically significant differences with respect to the empty plasmid group. Significant differences are displayed as $* * *(0.0001<\mathrm{p}<0.001), * *(0.001<$ $\mathrm{p}<0.01)$ or $*(0.01<\mathrm{p}<0.05)$. Ctrl $=$ Control.

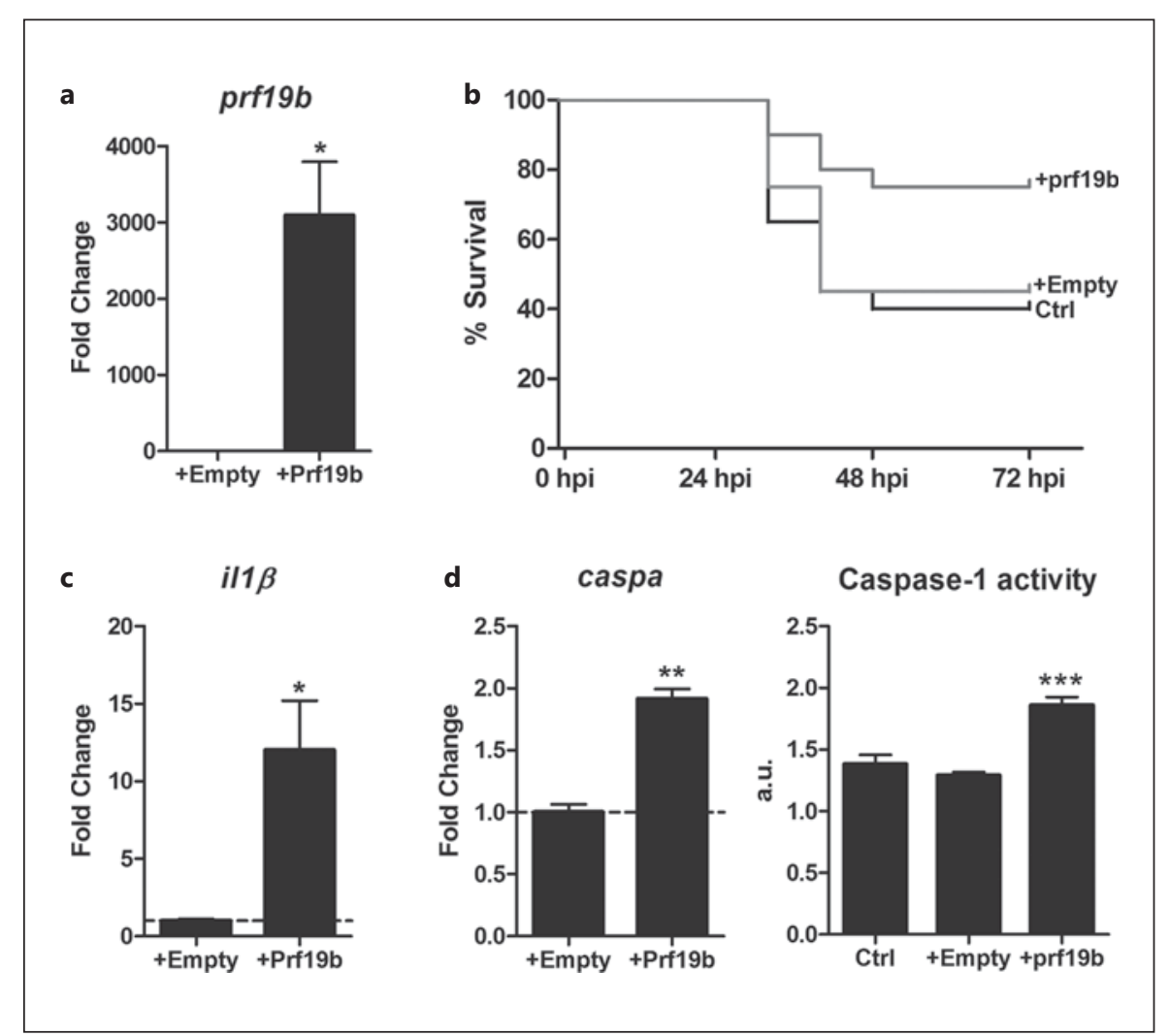

quenced lamprey genomes did not allow more precision in the analysis.

Our results suggest that prf $19 b$ probably evolved first from the common precursor of C6-C9 and PRF, corresponding to a one-to-one ortholog of mammalian PRF1, and possibly being the ancestor gene. Undoubtedly, improvement in the currently published genomes and new species genome sequencing projects will help to support the conclusions we have drawn. Until then, it is advisable to be cautious when suggesting similar functions and inferring orthologous relationships with distant fish species, especially in such a highly dynamic and active gene family as perforins. Furthermore, deeper study of evolutionary events such as concerted evolution or site-specific selection pressure may help to explain the variability and evolution of this gene family.

As D'Angelo et al. [7] wondered, the question is: Why do fish require so many perforins in contrast to mammals (in which a single gene is enough for correct cytotoxic lymphocyte function)? Our results indicate that the 6 zebrafish perforin genes were expressed under basal conditions in all analyzed tissues, contrary to what has been reported for Japanese flounder and trout, in which perfo- rin mRNA was not detected in liver samples $[8,9]$. However, the tissue distribution was different for each perforin gene. Whereas certain genes, such as prf $8 a$, showed broad expression across different tissues, other perforins were more tissue-specific, such as prf $8 b$ in the muscle or prf19a in the spleen and kidney. These differential expression profiles were also detected to be constitutive during the first month of zebrafish larval development, suggesting possible functional differences or different cellular locations. Cellular ontogeny in zebrafish is a well-characterized process [34], and it is known that larvae do not acquire a completely functional immune system until the 4th-6th week of development [35]. This phenomenon may be related to the expression peaks observed around the 4 th week of development in several of the zebrafish perforin genes.

When we analyzed the expression of the 6 perforin genes at the cellular level in the main hematopoietic tissue of fish, we confirmed that the perforins were expressed in the kidney lymphoid and myeloid cell populations. In mammals, perforin is primarily produced by natural killer T cells and cytotoxic T lymphocytes, but it is also expressed by human alveolar macrophages [36]. In zebraf- 
ish, as expected, the lymphoid population showed the highest perforin expression, with prf $3 b$ expression being the most remarkable, accounting for $23 \%$ of the total. In the myeloid population, prf $19 b$ expression was high, accounting for $18 \%$ of the total. This finding could be related to the possible role of prf $19 b$ as an ancestral perforin. This perforin might therefore be similar to mpeg1, which is expressed mainly in macrophages [37]. Interestingly, rainbow trout perforin is also induced in the monocyte/ macrophage-like RTS-11 cell line after viral hemorrhagic septicemia virus infection [38], suggesting that teleost perforins are commonly expressed in the myeloid cell population. These results also agreed with our results obtained in $\mathrm{RAG}^{-1-}$ mutant zebrafish, which have a reduced lymphocyte-like cell population [39]. $\mathrm{RAG1}^{-/-}$fish have more perforin mRNAs in the kidney than RAG1 $1^{+/+}$ fish, including more expression of prf19b, which is probably related to their increased myelomonocyte population compared with that of $\mathrm{RAG}^{+/+}$fish [40]. This finding again suggests that prf $19 b$ could be more specific to the myeloid population.

The evaluation of the in vivo effects of LPS, poly I:C and SVCV in kidney cells showed us different response patterns across the zebrafish perforin genes. Several of the perforin genes seemed to respond in the same way, independently of the stimuli used, but the prf $19 b$ response appeared to be more stimulus-specific because there was a significant increase in its expression after infection with a viral pathogen. After systemic infection with the rhabdovirus SVCV, zebrafish larvae modulated their perforin gene expression, with a particular increase in prf $3 b$ and prf19b expression toward the end of the infection.

From our results, we can conclude that prf19b, which appeared to be differentially expressed in the myeloid cell population, is probably the perforin gene that is closest to the macrophage MPEG1 gene and is therefore the putative perforin ancestor. Interestingly, this gene was the main one that responded to viral infection both in adult kidney and after systemic infection of zebrafish larvae. As we recently described the importance of the inflammatory response mediated by macrophages during an infection with SVCV in zebrafish larvae [31], we further investigated the role of prf19b during this viral infection. Overexpression of prf19b in zebrafish larvae before the infection with SVCV induced protection against the virus. Although further research is needed to fully understand the mechanism involved, the increased caspase-1 activity and the expression of caspa and ill $\beta$ could have a role in relation to inflammasome activation and pyroptotic cell death. The inflammasome platform is conserved across vertebrate phylogeny, therefore zebrafish present all the components of this mechanism [32]. The appearance of pores in the membrane of cells is one of the hallmarks of pyroptotic cell death [41], and membrane permeability and channel formation have been shown to trigger inflammasome activation [42]. In fact, it has been recently reported that the membrane attack complex of complement pores triggers inflammasome activation in the cytosol [43]. Whether the potassium and calcium mobilization induced by perforin [44] is associated with inflammasome activation and pyroptosis [45, 46], and eventually antiviral activity, is a topic that deserves further study.

The perforin identified as a perforin precursor in our study, prf19b, retained an expression pattern similar to that of MPEG1, the gene from which the perforin family evolved. Furthermore, prf19b induced protection against a viral infection but further research is needed to understand if inflammasome activation could be involved in this resistance, as do the evolutionarily related complement molecules. Perforin genes arising subsequently showed different expression patterns which, as in the case of prf $3 b$, were more similar to the results expected based on the data available for humans. It seems that the diversification that occurred during the evolution of this family probably affected the functionality and cellular localization among species.

\section{Acknowledgments}

This work was funded by the projects CSD2007-00002 'Aquagenomics' and AGL2014-51773-C3 from the Spanish Ministerio de Economía y Competitividad. M. Varela received a predoctoral grant from the JAE Program (funded by the CSIC and European Social Funds).

References

Thiery J, Lieberman J: Perforin: A key poreforming protein for immune control of viruses and cancer. Subcell Biochem 2014;80:197220.

2 Trapani JA, Smyth MJ: Functional significance of the perforin/granzyme cell death pathway. Nat Rev Immunol 2002;2:735-747.

-3 Voskoboinik I, Smyth MJ, Trapani JA: Perforin-mediated target-cell death and immune homeostasis. Nat Rev Immunol 2002;6:940 952.

4 Keefe D, Shi L, Feske S, Massol R, Navarro F, Kirchhausen T, Lieberman J: Perforin triggers a plasma membrane-repair response that facilitates CTL induction of apoptosis. Immunity $2005 ; 23: 249-262$. 
-5 Lopez JA, Brennan AJ, Whisstock JC, Voskoboinik I, Trapani JA: Protecting a serial killer: pathways for perforin trafficking and self-defence ensure sequential target cell death. Trends Immunol 2012;33:406-412.

-6 Spilsbury K, O’Mara MA, Wu WM, Rowe PB, Symonds G, Takayama Y: Isolation of a novel macrophage-specific gene by differential cDNA analysis. Blood 1995;85:1620-1629.

7 D’Angelo ME, Dunstone MA, Whisstock JC, Trapani JA, Bird PI: Perforin evolved from a gene duplication of MPEG1, followed by a complex pattern of gene gain and loss within Euteleostomi. BMC Evol Biol 2012;12:59.

$>8$ Hwang JY, Ohira T, Hirono I, Aoki T: A poreforming protein, perforin, from a nonmammalian organism, Japanese flounder, Paralichtys olivaceus. Immunogenetics 2004; 56:360-367.

$\checkmark 9$ Praveen K, Leary JH 3rd, Evand DL, JasoFriedmann L: Nonspecific cytotoxic cells of teleosts are armed with multiple granzymes and other components of the granule exocytosis pathway. Mol Immunol 2006;43:11521162.

10 Athanasopoulou S, Marioli D, Mikrou A, Papanastasiou AD, Zarkadis IK: Cloning and characterization of the trout perforin. Fish Shellfish Immunol 2009;26:908-912.

-11 Toda H, Araki K, Moritomo T, Nakanishi T: Perforin-dependent cytotoxic mechanism in killing by CD 8 positive T cells in ginbuna crucian carp, Carassius auratus langsdorfii. Dev Comp Immunol 2011;35:88-93.

12 Campanella JJ, Bitincka L, Smalley J: MatGAT: an application that generates similarity/identity matrices using protein or DNA sequences. BMC Bioinformatics 2003;4:29.

$>13$ Jones P, Binns D, Chang HY, Fraser M, Li W, McAnulla C, McWilliam H, Maslen J, Mitchell A, Nuka G, Pesseat S, Quinn AF, SangradorVegas A, Scheremetjew M, Yong SY, Lopez R, and Hunter S: InterProScan 5: genome-scale protein function classification. Bioinformatics 2014;30:1236-1240.

14 Käll L, Krogh A, Sonnhammer EL: A combined transmembrane topology and signal peptide prediction method. J Mol Biol 2004; 338:1027-1036.

15 Roy A, Kucukural A, Zhang Y: I-TASSER: a unified platform for automated protein structure and function prediction. Nat Protoc 2010;5:725-738.

-16 Flicek P, Amode MR, Barrell D, et al: Ensembl 2012. Nucleic Acids Res 2012;40:D84-D90.

17 Forn-Cuní G, Reis ES, Dios S, Posada D, Lambris JD, Figueras A, Novoa B: The evolution and appearance of C3 duplications in fish originate an exclusive teleost $\mathrm{c} 3$ gene form with anti-inflammatory activity. PLoS One 2014;9:e99673.
Maddison WP: Gene trees in species trees. Syst Biol 1997;46:523-536.

19 Page RD, Charleston MA: From gene to organismal phylogeny: reconciled trees and the gene tree/species tree problem. Mol Phylogenet Evol 1997;7:231-240.

20 Hedges SB, Dudley J, Kumar S: TimeTree: a public knowledge-base of divergence times among organisms. Bioinformatics 2006;22: 2971-2972.

21 Sjostrand J, Sennblad B, Arvestad L, Lagergren J: DLRS: gene tree evolution in light of a species tree. Bioinformatics 2012;28:2994-2995.

22 Paradis E, Claude J, Strimmer K: APE: analyses of phylogenetics and evolution in R language. Bioinformatics 2004;20:289-290.

23 Sennblad B, Schreil E, Berglund Sonnhammer, AC, Lagergren J, Arvestad L: primetv: a viewer for reconciled trees. BMC Bioinformatics 2007;8:148.

24 Westerfield M: The Zebrafish Book. A Guide for the Laboratory Use of Zebrafish (Danio rerio), ed 4. Eugene, University of Oregon Press, 2000 .

25 Nusslein-Volhard C, Dahm R: Zebrafish, a Practical Approach, ed 1. Oxford, Oxford University Press, 2002.

26 Reed LJ, Muench H: A simple method for estimating fifty percent end points. Am J Epidemiol 1938;27:493-497.

27 Benard EL, van der Sar AM, Ellett F, Lieschke GJ, Spaink HP, Meijer AH: Infection of zebrafish embryos with intracellular bacterial pathogens. J Vis Exp 2012;61:e3781.

28 Traver D, Paw BH, Poss KD, Penberthy WT, Lin S, Zon LI: Transplantation and in vivo imaging of multilineage engraftment in zebrafish bloodless mutants. Nat Immunol 2003; 4(12): 1238-1246.

29 Varela M, Dios S, Novoa B, Figueras A: Characterisation, expression and ontogeny of interleukin-6 and its receptors in zebrafish ( $\mathrm{Da}$ nio rerio). Dev Comp Immunol 2012;37:97106.

30 Wienholds E, Merker SS, Walderich B, Plasterk RHA: Target-selected inactivation of the zebrafish rag1 gene. Science 2002;297:99-101.

31 Varela M, Romero A, Dios S, van der Vaart M, Figueras A, Meijer AH, Novoa B: Cellular visualization of macrophage pyroptosis and interleukin- $1 \beta$ release in a viral hemorrhagic infection in zebrafish larvae. J Virol 2014;88: 12026-12040.

32 Vojtech LN, Scharping N, Woodson JC, Hansen JD: Roles of inflammatory caspases during processing of zebrafish interleukin-1b in Francisella noatunensis infection. Infect Immun 2012;80:2878-2885.

33 Law RH, Lukoyanova N, Voskoboinik I, Caradoc-Davies TT, Baran K, Dunstone MA, D'Angelo ME, Orlova EV, Coulibaly F, Ver- schoor S, et al: The structural basis for membrane binding and pore formation by lymphocyte perforin. Nature 2010;468:447-451.

34 Zapata A, Diez B, Cejalvo T, Gutiérrez-de Frías C, Cortés A: Ontogeny of the immune system of fish. Fish Shellfish Immunol 2006; 20:126-136.

35 Lam SH, Chua HL, Gong Z, Lam TJ, Sin YM: Development and maturation of the immune system in zebrafish, Danio rerio: a gene expression profiling, in situ hybridization and immunological study. Dev Comp Immunol 2004;28:9-28.

36 Burnham EL, Phang TL, House R, Vandivier RW, Moss M, Gaydos J: Alveolar macrophage gene expression is altered in the setting of alcohol use disorders. Alcohol Clin Exp Res 2011;35:284-294.

37 Ellett F, Pase L, Hayman JW, Andrianopoulos A, Lieschke GJ: MPEG1 promoter transgenes direct macrophage-lineage expression in zebrafish. Blood 2011;117:e49-e56.

38 Ordás MC, Cuesta A, Mercado L, Bols NC, Tafalla C: Viral hemorrhagic septicaemia virus (VHSV) up-regulates the cytotoxic activity and the perforin/granzyme pathway in the rainbow trout RTS11 cell line. Fish Shellfish Immunol 2011;31:252-259.

39 Hohn C, Petrie-Hanson L: Rag1-/- mutant zebrafish demonstrate specific protection following bacterial re-exposure. PLoS One 2012; 7:e44451.

40 Petrie-Hanson L, Hohn C, Hanson L: Characterization of rag1 mutant zebrafish leukocytes. BMC Immunol 2009;10:8.

41 Fink SL, Cookson BT: Apoptosis, pyroptosis, and necrosis: mechanistic description of dead and dying eukaryotic cells. Infect Immun 2005;73:1907-1916.

42 Ichinohe T, Pang IK, Iwasaki A: Influenza virus activates inflammasomes via its intracellular M2 ion channel. Nat Immunol 2010;11: 404-410.

43 Triantafilou K, Hughes TR, Triantafilou M, Morgan BP: The complement membrane attack complex triggers intracelular $\mathrm{Ca}^{2+}$ fluxes leading to NLRP3 inflammasome activation. J Cell Sci 2013;126:2903-2913.

44 Stewart SE, Kondos SC, Matthews AY, D'Angelo ME, Dunstone MA, Whisstock JC, Trapani JA, Bird PI: The perforin pore facilitates the delivery of cationic cargos. J Biol Chem 2014;289:9172-9181.

45 Dagenais M, Skeldon A, Saleh M: The inflammasome: in memory of Dr. Jurg Tschopp. Cell Death Differ 2012;19:5-12.

46 Murakami T, Ockinger J, Yu J, Byles V, McCol A, Hofer AM, Horng T: Critical role for calcium mobilization in activation of the NLRP3 inflammasome. Proc Natl Acad Sci U S A 2012;109:11282-11287. 